\title{
Abordagem terapêutica grupal com mães de crianças portadoras de distúrbios de linguagem
}

\author{
Group therapy approach with mothers of children with \\ language impairment
}

\author{
Fernanda Marafiga Wiethan¹, Ana Paula Ramos de Souza², Ellen Fernanda Klinger ${ }^{3}$
}

\begin{abstract}
RESUMO
O objetivo deste estudo foi investigar a eficiência da abordagem grupal com mães de sujeitos com distúrbios de linguagem para promover mudanças na interação dialógica da díade mãe-filho. Fizeram parte do estudo quatro díades mãe-criança. Os procedimentos constituíram-se de entrevista inicial com as mães e filmagem das díades em situação de interação antes e após a intervenção terapêutica, para interpretação do discurso materno e da atividade dialógica, bem como verificação da eficácia das sessões em grupo. O grupo terapêutico constituiu-se de oito encontros com as mães destas crianças, nos quais se discutiram temas variados acerca do desenvolvimento infantil. Os resultados mostraram que a intervenção provocou melhorias na interação mãe-filho. A intervenção terapêutica grupal auxiliou as mães no exercício da função materna, dando acolhimento às suas demandas, mostrando-se também, uma alternativa importante em clínicas do sistema público de saúde, à medida que pode reduzir a espera para atendimento fonoaudiológico.
\end{abstract}

Descritores: Fonoterapia; Mães; Criança; Transtornos da linguagem; Relações mãe-filho; Psicoterapia de grupo

\section{INTRODUÇÃO}

Nos últimos anos, tem-se observado em clínicas de Fonoaudiologia, sejam elas públicas ou privadas, a crescente demanda de atendimento a crianças encaminhadas com queixa de "não falar" ou apresentar produções ininteligíveis. Estas ocorrências, na prática fonoaudiológica, caracterizam-se como atraso, distúrbio, ou retardo de linguagem, a depender da linha teórica que norteie o trabalho de linguagem.

Na concepção interacionista, o retardo na aquisição da linguagem é visto como um funcionamento particular em meio ao funcionamento geral da linguagem. Essa concepção reconhece a heterogeneidade e imprevisibilidade dos efeitos da fala das crianças, que não seguem aquele padrão previsto nas etapas cronológicas de desenvolvimento ${ }^{(1)}$. Nesta perspectiva,

Trabalho realizado na Clínica Escola do Serviço de Atendimento Fonoaudiológico do Centro de Ciências da Saúde da Universidade Federal de Santa Maria - UFSM - Santa Maria (RS), Brasil.

(1) Pós-graduanda (Mestrado) em Distúrbios da Comunicação Humana da Universidade Federal de Santa Maria - UFSM - Santa Maria (RS), Brasil.

(2) Doutora, Professora Adjunto do Curso de Graduação em Fonoaudiologia e do Mestrado em Distúrbios da Comunicação Humana da Universidade Federal de Santa Maria - UFSM - Santa Maria (RS), Brasil.

(3) Pós-graduanda (Mestrado) em Distúrbios da Comunicação Humana da Universidade Federal de Santa Maria - UFSM - Santa Maria (RS), Brasil.

Endereço para correspondência: Fernanda Marafiga Wiethan. R. Júlio Nogueira, 130, Uglione, Santa Maria (RS), Brasil, CEP: 97070-510. E-mail: fernanda_wiethan@yahoo.com.br

Recebido em: 1/6/2009; Aceito em: 15/9/2009 ficam secundárias as tipologias de retardo. Tais aspectos são encarados como limites biológicos e não se constituem como cerne do processo terapêutico com os pais, embora devam ser considerados no processo terapêutico como um todo.

A inibição em falar pode demonstrar, além de um desajuste familiar, a impotência da criança em identificar-se e reconhecer-se como si mesma, em distinguir-se socialmente, ou seja, em estruturar-se como sujeito ${ }^{(2)}$.

Nesse sentido, acredita-se que a abordagem teórica que tome a família como centro da intervenção poderá possibilitar progressos maiores aos sujeitos portadores de retardos de linguagem ${ }^{(3)}$. A proposta interacionista pode assumir tal perspectiva, na medida em que elege a díade mãe-criança ou cuidador-criança como foco de análise da linguagem do sujeito com queixa de retardo de aquisição da linguagem. Considerando tal visão teórica, não será realizada a distinção do subtipo de distúrbio de linguagem, salvo se utilizem autores que priorizem o uso de uma terminologia específica ${ }^{(4-7)}$, uma vez que tal terminologia não é utilizada na bibliografia interacionista, enquadre teórico deste artigo. Do ponto de vista interacionista, os casos aqui relatados seriam identificados como retardos de aquisição da linguagem. Já do ponto de vista cognitivista seriam distúrbios específicos da linguagem*.

$\mathrm{Na}$ visão psicanalítica, afirma-se como frequente a ocorrên-

\footnotetext{
* Dos quatro casos analisados, três foram diagnosticados como DEL, subtipo dispráxico, e um como atraso de linguagem, considerando-se autores desta vertente teórica ${ }^{(10,11)}$.
} 
cia de um laço psicopatológico dos pais à criança, o que não permite sua subjetivação, fundamental para o desenvolvimento sadio da linguagem. O "não falar" também pode constituir-se como um recurso neurótico, por parte da criança, uma reivindicação da presença e dos cuidados do outro ${ }^{(2)}$. Em relação à subjetivação, o rompimento ou enfraquecimento da relação de identificação entre a criança e a mãe (ou quem exerça esta função) é que dá a possibilidade da criança de constituir-se como sujeito na/pela linguagem ${ }^{(1,3,8)}$. Quando tal descolamento não ocorre, pode surgir o distúrbio de linguagem. Nesses casos, o olhar "patologizante" dos pais à criança e a ausência da escuta e do olhar para suas evoluções, configuram-se como impedimentos para o desenvolvimento sadio de linguagem ${ }^{(9)}$.

Uma vez que o distúrbio de linguagem é uma condição de instalação precoce ${ }^{(10,11)}$, acredita-se que quanto mais cedo seja iniciada a intervenção, mais favorável será a evolução dos casos. Somado a isto, é necessário considerar a importância da atividade dialógica, e os problemas que a falta ou ineficiência desta causam, tanto no âmbito familiar quanto social. Isto deve ser considerado, uma vez que a própria condição de infans já autoriza o adulto a assumir a responsabilidade pelo "falar", ou seja, a criança depende do que dizem dela, sendo isto potencializado em casos de ausência de fala ${ }^{(2)}$. Assim, verifica-se a necessidade de se implementarem estratégias de intervenção essencial.

Desta forma, julga-se importante abordar a teoria interacionista, uma vez que esta rege os procedimentos utilizados neste trabalho. Tal teoria defende que é pela atividade dialógica entre a criança e o outro que a cognição e a linguagem são construídas. A aquisição da linguagem define-se pela possibilidade de ocupar distintas posições numa estrutura cujos pólos são o outro, a língua e o próprio sujeito ${ }^{(12)}$. Assim, o fonoaudió$\operatorname{logo}$, ainda que afetado pela fala da criança, coloca-se como intérprete desta, quebrando o que aprisiona o sujeito em seu sintoma de linguagem ${ }^{(1,3)}$.

A teoria interacionista, no âmbito da Fonoaudiologia, prevê que sejam adotadas abordagens de intervenção centradas na criança e/ou nos pais, além do atendimento em grupo ${ }^{(13)}$. Na abordagem com foco na criança, a interação se dá entre paciente e terapeuta, de forma individual. Já a intervenção com foco nas mães, adotada neste trabalho, consiste na realização de entrevistas e debates continuados com os pais das crianças acerca dos temas relacionados à queixa que gerou a busca pelo atendimento, bem como dar acolhimento e respostas a questionamentos. Esta abordagem é uma forma de fomentar uma reflexão profunda sobre o exercício das funções e sentimentos parentais para com a criança e como transcendê-los, pois a "boa estimulação" está calcada em uma relação flexível entre o filho real e o imaginado e passa pelos desejos parentais relacionados a esta criança ${ }^{(3)}$.

Este tipo de intervenção pode ser uma estratégia produtiva durante o período em que as crianças aguardam atendimento nos serviços públicos, podendo significar tanto a minimização da problemática de linguagem quanto a sua resolução. Pode ter como consequência a redução das filas de espera para atendimento fonoaudiológico, em que os próprios familiares é que estarão colaborando para a evolução das crianças, funcionando como agentes ativos do processo terapêutico, além da importância que a identificação grupal tem para o indivíduo ${ }^{(14)}$.
Além disso, os sintomas de linguagem estão geralmente associados às dificuldades parentais ${ }^{(15)}$, que necessitam ser superadas para que se inicie o processo de subjetivação da criança ${ }^{(2)}$. A discussão em grupo pode servir como um momento de reflexão e alívio para as ansiedades e fantasmas maternos. Este recurso é uma estratégia de saúde coletiva, configurando-se como promoção da saúde, pois tem como objetivos maximizar o potencial dos indivíduos, por meio de um olhar abrangente para o desenvolvimento humano. A promoção se dá a partir da identificação das necessidades e condições de vida das pessoas, atentando para as diferenças, singularidades e subjetividades implicadas nos acontecimentos individuais e coletivos de saúde ${ }^{(14)}$.

Tendo em vista o exposto, o objetivo deste trabalho foi investigar a eficiência da abordagem grupal com mães de sujeitos com distúrbios de linguagem para promover mudanças na interação dialógica da díade mãe-filho.

\section{APRESENTAÇÃO DO CASO CLÍNICO}

Este trabalho é parte do projeto "Clínica da Subjetividade nos Retardos da Aquisição da Linguagem Oral", aprovado no comitê de ética da Universidade Federal de Santa Maria (UFSM) sob protocolo número 0117.0.243.000-07.

A população da pesquisa constituiu-se de crianças, cujas mães apresentavam a queixa de "falar pouco" ou "não falar". Com a evolução dos sujeitos foi possível fazer um diagnóstico mais específico do seu distúrbio de linguagem: poderiam ser enquadrados na descrição de DEL, sendo três no subtipo dispraxia verbal. Como tal descrição não era possível ao início da intervenção, nem se faz fundamental na abordagem teórica escolhida, identificaram-se quadros que permitiram excluir deficiência auditiva, lesões neurológicas e transtornos do espectro autístico, ou seja, todos os sujeitos brincavam simbolicamente, mantinham comunicação não verbal com o interlocutor e não possuíam alterações auditivas ou motoras de tipo lesional.

As mães assinaram o Termo de Consentimento Livre e Esclarecido, autorizando a realização da pesquisa. Foram garantidos os direitos de confidencialidade de suas identidades e voluntariado. Destaca-se que todos os participantes desta pesquisa foram encaminhados, na sequência da intervenção com as mães, para avaliações complementares e terapia individual, sobretudo aqueles que não superaram os sintomas de linguagem depois da intervenção aqui relatada.

\section{Descrição dos procedimentos}

A coleta iniciou-se por entrevista com as mães, na qual se buscou escutar o discurso destas sobre a gestação, desenvolvimento da criança e histórico clínico, expectativas que apresentaram e/ou apresentam com relação ao filho, comportamento atual da criança, bem como sua linguagem e desenvolvimento, histórico e dinâmica familiar, do ponto de vista psico-sócio-econômico-cultural. A entrevista deu-se de modo semi-estruturado, buscando-se facilitar o discurso contínuo da mãe acerca dos aspectos apontados anteriormente. Para tanto, elaborou-se um roteiro sobre os temas a serem abordados, cuja 
efetivação deu-se de modo individualizado, a cada entrevistada, permitindo maior entrosamento entre a pesquisadora e as participantes, propiciando uma relação horizontal entre estas, conforme é preconizado na abordagem escolhida.

Posteriormente, foi realizada avaliação da interação dialógica entre mãe e filho. A interpretação da atividade dialógica deu-se embasada na teoria interacionista de $\operatorname{Lemos}^{(12)}$ e como teoria de subjetividade a psicanálise ${ }^{(2,8)}$. A partir de tal perspectiva teórica, as interações das díades mãe-criança foram filmadas para análise dos processos dialógicos, sobretudo o funcionamento dos processos metafóricos e metonímicos, procurando-se verificar as posições discursivas ocupadas pela criança na relação com a mãe.

Assim, iniciou-se o grupo com as mães dessas crianças. Nele, manteve-se o mesmo enquadre teórico em linguagem (interacionista, atravessado pela psicanálise) e como tipo de grupo o operativo, com relação horizontal, anteriormente mencionada. Após o término das sessões em grupo, as interações dialógicas mãe-criança foram reavaliadas com o mesmo procedimento da primeira avaliação, para que fosse verificada a efetividade ou não, da abordagem terapêutica grupal com as mães, buscando-se detectar possíveis melhorias na interação da díade mãe-filho, assim como evoluções na aquisição da linguagem das crianças.

Para a análise, foram consideradas a transcrição da filmagem e algumas observações adicionais das mães com as crianças sem a filmagem, já que aquela pode criar um momento artificial. De modo geral, tais observações confirmaram o que se viu na filmagem. A partir da transcrição, foram selecionadas algumas seqüências que servissem para exemplificar o que era característica principal do diálogo mãe-filho, ou seja, que ocupassem mais de $70 \%$ da transcrição. Portanto, o critério de seleção dos trechos apresentados nos resultados foi qualitativo, e considerou a percepção geral dos autores a respeito de cada díade, o exemplo mais claro ao leitor e o espaço delimitado para o relato de caso.

\section{Histórico e análise inicial das interações dialógicas das díades}

\section{Díade 1}

Formada por M1 (31 anos) e S1 (três anos e cinco meses ao início da pesquisa). A mãe engravidou de $\mathrm{S} 1$ aos 27 anos, embora não pretendesse ter filhos antes dos 30 . No entanto, diz que o menino foi bem recebido por toda a família (sogro, sogra e marido). A maior expectativa era de que fosse saudável: "Eu só queria que ele fosse saudável e que puxasse por mim". Durante a gravidez, passou por períodos de elevado estresse, em razão da agressividade do sogro, alcoolista, com a sogra, em cuja residência co-habitavam. Também tinha receio de que o menino herdasse o traço de agressividade do pai, que ela atribui à super proteção recebida da mãe dele. Atualmente, M1 incomoda-se por ter de proteger o filho dos "ataques de fúria" do marido e também identifica certo "pavio curto" no menino. Sua descrição do filho é, nesse sentido, contraditória: "Ele é uma criança linda, maravilhosa, mas tá mal criado pela vó, pelo pai e pelos tios. Ele tem uma fúria e gruda as coisas na gente. Eu fico muito nervosa porque eu não sei se é eu que passo isso pra ele, acho que eu fico cobrando muito pra ele falar. É que eu escuto de todo mundo: teu filho tá atrasado".

No trecho descrito, a mãe deixa claro que apresenta muita ansiedade em relação à fala do menino e a aspectos de comportamento semelhantes ao pai. Esse fato se materializa na interação dialogal, conforme Sequência 1:

M1: O que que é isso aqui?

S1: (Olha para o brinquedo que a mãe mostra e fala algo ininteligível)

MI: Ó! $G i-r a-f a$ ! (movimenta a girafa e faz onomatopéia)

S1: (Continua olhando para o objeto que a mãe mostra e sorri)

M1: Que que é isso? (Pega no rosto da criança para que ele a olhe)

S1: (imita a onomatopéia e o gesto da mãe. Após afasta-se da mãe levando consigo o brinquedo)

M1: Não é girafa?

S1: Não! (continua na mesma posição)

Pode-se observar nesta sequência, a insistência da mãe em fazer com que o menino nomeasse os objetos, correspondendo ao discurso dela na entrevista em relação às cobranças que faz ao filho. S1, por sua vez, "foge" de todas as tentativas da mãe, ora virando-se de costas para ela, ora negando suas afirmações ou ignorando suas perguntas. Em muitos momentos, o menino toma a iniciativa de interação, mas parece desistir diante de não corresponder às expectativas maternas. Também se pode perceber o olhar da criança dirigido à mãe, no entanto, parece que ela não está à vontade neste momento, não conseguindo se conectar ao filho. Observou-se que a mãe reprova as atitudes de S1, dando a entender que ele não sabe brincar, conforme exposto no fragmento: "Pára que assim tu vai estragar, brinca com jeito." Estes comportamentos predominaram nesta primeira filmagem.

\section{Díade 2}

M2, hoje com 28 anos, engravidou de S2 (três anos e três meses ao início da pesquisa) quando estava com 25 anos e relata não ter planejado a gravidez: "Foi um pouco tumultuado, mas depois tudo se ajeitou". Foi um período de grande nervosismo e, a exemplo de M1, desejava que o bebê fosse saudável. O parto foi de cesariana e o relato leva a crer que houve anóxia perinatal, embora não haja sinais visíveis de lesão. Afirma, quando indagada sobre as primeiras reações em relação ao bebê: "Eu tinha curiosidade de ver o rostinho, as características... Os bebezinho são bonitinhos... Ele foi muito bem recebido". Foi amamentado até um ano e quatro meses de idade, quando a mãe começou a trabalhar. Ainda dorme no quarto dos pais e é muito agitado durante a noite. A mãe afirma que ele dorme com eles porque S2 sofreu de anemia e isso a fazia ter medo de deixá-lo dormir sozinho. A fala surgiu com um ano e seis meses (mãe, pai) o que deixa a mãe oscilante quanto a existir ou não alteração de linguagem: "às vezes eu acho um pouco normal, às vezes eu acho um pouco atrasado", atribuindo esta problemática à genética: "O irmão do meu marido foi falar com cinco anos". A mãe afirma que o relacionamento familiar é bom, embora o pai a desautorize na educação de S2, superprotegendo-o. Também conta que S2 é 
bem "ativo, entende tudo e é bem esperto", se desobedece ela diz: "Coloco ele de castigo na cadeira, olhando TV. Ele adora o Pica-pau, fica um tempão olhando". Esse fato demonstra o quanto a questão de limites não é só problemática para o pai.

A interação inicial de M2 e S2 pode ser observada na Sequência 2:

S2: (vai em direção a um carrinho e começa a brincar com ele)

M2: Cadê a roda?

S2: Aqui roda! (mostra a roda)

M2: E o pneu?

S2: Ó! (aponta aleatoriamente, partes do carro)

M2: Não! E o pneu?

S2: Hãn? É aqui (mostra algo aleatoriamente novamente)

M2: $A$ h!

Neste trecho percebe-se que esta mãe é bastante diretiva (na forma de comandos, solicitando brinquedos), não permitindo que $\mathrm{S} 2$ brinque. Faz muitas perguntas com respostas, solicitando informações e pedindo ações. Observou-se uma fala, por parte da mãe, bastante articulada e pausada, demonstrando a preocupação em ensinar o filho a falar corretamente. O menino, da mesma forma que S1, esquiva-se destes comportamentos. Percebe-se que S2 se utiliza muito de gestos, que na maioria das vezes são bastante efetivos na comunicação. A criança tenta a comunicação verbal, mas sua fala na maioria das vezes é ininteligível.

\section{Díade 3}

Formada por M3 (41 anos) e S3 (dois anos e nove meses ao início da pesquisa). A mãe engravidou de $\mathrm{S} 3$ aos 38 anos, sendo a gravidez de risco, porém ela não pôde fazer repouso, pois precisava trabalhar. A gravidez não foi planejada, sendo considerada "um susto" para os pais da criança. M3 já tinha outros três filhos (foi mãe aos 14 anos), duas gêmeas e um rapaz, que na época estavam com 24 e 15 anos, respectivamente. Durante a cesariana, M3 sofreu uma hemorragia, tendo que realizar uma cirurgia após o parto, fato que dificultou que ela visse o filho e que o amamentasse. $\mathrm{S} 3$ faz uso de mamadeira e chupeta.

Desde que S3 tinha um ano de idade, M3 está separada do pai do menino. A criança dorme no quarto da mãe porque a casa não tem espaço e, muitas vezes, vai para a cama dela à noite. Sobre o atraso de linguagem, M3 referiu: "Tenho medo que ele nunca vai falar, mas se eu tiver que ter um filho mudo, eu vou aceitar né? Daí quando ele tiver idade, ele aprende os sinais". M3 acredita que o atraso de linguagem se deva a um trauma sofrido quando o menino tinha um ano de idade e estava começando a falar: "O pai dele é meio louco e não aceita a nossa separação. O S3 tava começando a falar, daí o pai dele chegou lá em casa quebrando tudo e queria derrubar a porta e o guri vendo tudo isso só gritava, porque lá em casa, ninguém é assim, ele não é acostumado com isso".

A interação inicial de M3 e S3 pode ser observada na Sequência 3:

M3: (Pega uma boneca)

S3: (Olha para a boneca que a mãe pegou)

M3: Faz o papá. Dá papá pra menininha, dá.

S3: (Analisa a colher e mexe o "líquido" da xícara. Pega a xícara e balança a cabeça negativamente)
M3: (Mãe observa) Que tu tá fazendo? Diz pra mamãe que 'cề' ta fazendo, papá?

S3: (Observa a sala)

M3: Diz papá.

S3: Papô.

M3: Agora dá papá pro neném.

S3: (finge comer o papá)

Nesta díade, foram observados longos períodos de silêncio durante a interação, além disso, M3 volta sua atenção para que o menino fale o que ela deseja, compreenda e atenda seus pedidos de ação. A mãe interagia com a S3 de forma desinteressada e não parecia estar à vontade na situação de brinquedo. No comportamento da criança observa-se infantilização, especialmente no trecho em que a mãe solicita que ele dê "papá" para o bebê, e ele próprio é quem finge comer. Das quatro crianças, $\mathrm{S} 3$ foi o que menos mostrou intenção comunicativa.

\section{Díade 4}

Composta por M4 (40 anos) e S4 (três anos e cinco meses ao início da pesquisa). Quanto à gestação, a mãe tinha 37 anos quando engravidou. Ela já tinha dois filhos do primeiro casamento, uma menina e um menino que, atualmente, estão com 12 e 11 anos, respectivamente. A gravidez não foi planejada e a mãe sentiu-se apreensiva quando descobriu. A expectativa de M4, da mesma forma que as outras mães, era de que o bebê nascesse saudável. A adaptação com o bebê foi tranquila: "Ele sempre foi calminho, nunca incomodou. Só o irmão dele que tinha muito ciúmes". Apesar do ciúme, os dois irmãos ficaram muito felizes.

Sobre a linguagem, a mãe não soube fornecer informações precisas, por não lembrar, uma vez que trabalhava fora na época e o menino ficava com a babá. Ela lembra que ele começou a falar após completar dois anos. Relacionado a isso, ela referiu: "Eu falei com a mãe e ela disse que é normal ele não falar porque eu só falei depois dos três anos e até hoje eu não gosto de falar porque eи erro umas palavras que não consigo dizer. Eu tenho a língua 'pêga', e o pai dele também demorou pra falar". Mesmo assim, a mãe não relaciona o atraso de linguagem à genética: "Acho que não é por isso. Ele se acostumou mal". Solicitou-se à mãe que definisse o filho: "Calmo, gosta de ver TV, quando quer as coisas pede. Mas, quando os irmãos chegam, ele agita. Adora o Tom e Jerry. Ele passa olhando". M4 usava medicamento antidepressivo e referiu ficar ansiosa e temerosa com situações novas.

Selecionou-se um segmento que ilustrasse a primeira interação de M4 e S4 (Sequência 4):

M4: (Pega um telefone) Tu não vai telefonar pro pai? Hein?

Tu não vai telefonar?

S4: (Explora um brinquedo)

M4: Telefona pro pai ó. S4! S4! Ô S4! Telefona pro pai.

S4: (Continua explorando o brinquedo)

M4: Tu não vai fazer café? Eu quero café. Tu não vai fazer café?

S4: (Permanece com o mesmo brinquedo e fala algo ininteligível)

M4: Café.

S4: Hãn!Hãn! (não) (Continua mexendo no brinquedo)

Percebeu-se que esta mãe, com o intuito de estimular o 
filho, inseria vários objetos que não eram foco de interesse da criança, além da cobrança excessiva em torno da fala, fazendo com que ele tentasse "escapar" das tentativas maternas. Também mostrou dificuldade para entrar no brincar com a criança que se defende e brinca só. Curiosamente, S4 é a criança que apresentou melhor linguagem oral e brincar simbólico mais constituído, e mesmo a mãe não participando da brincadeira, parece haver alguém que interaja brincando com o mesmo, tanto que pergunta várias vezes pelo irmão. $\mathrm{O}$ trecho inicial da sequência, em que a mãe tenta inserir o telefone no brinquedo, mostra o desejo que o menino fale.

\section{A intervenção e a evolução no grupo}

Os grupos foram semanais no período de agosto a setembro de 2008 (totalizando oito sessões) com duração de aproximadamente duas horas.

Nos grupos foi oportunizado que as mães debatessem temas de sua escolha, relacionados ao desenvolvimento infantil, em especial suas dúvidas e preocupações com os filhos. A pesquisadora procurou ressaltar a importância da atividade dialógica na construção da linguagem e das interpretações feitas acerca das manifestações interacionais que as crianças apresentam, procurando construir com as mães uma visão da sua importância no desenvolvimento de seus filhos ${ }^{(1,2)}$. Além de trocarem experiências no grupo, foram esclarecidas as dúvidas ou fantasmas maternos sobre questões biológicas.

Durante os encontros, M1 trouxe muitos comentários relacionados à sua vida pessoal, mostrando insatisfação e falta de espaço para discussão dos problemas em família, foi a mãe que mais trouxe questionamentos relacionados à fala, linguagem e comportamento, além disso, demonstrou acreditar que ter linguagem era "falar tudo certinho" e que o modo de favorecer isso era ensinar o nome dos objetos e as letras; M2 parecia ser consciente desde o início em relação à importância da atividade dialógica e do brincar na construção da linguagem e trouxe comentários bastante pertinentes às discussões realizadas, mostrando-se atenciosa e participativa, afirmando que "sempre é bom aprender mais um pouco. Aprender não ocupa espaço". Já M3 parecia duvidar da intervenção em grupo, porém em alguns encontros, da mesma forma que M1, trouxe queixas relacionadas à sua família. M4 foi a mãe mais calada durante os grupos, demonstrando timidez frente às outras participantes, porém, quando fazia comentários, demonstrava, a exemplo de M2, ter sensibilidade e boa compreensão para o que se abordava acerca da importância da relação vincular mãe-filho e suas consequências para a interação dialógica.

Todas as mães mostraram mudanças no decorrer do grupo, reduzindo a ansiedade em relação à linguagem dos filhos, à medida que discutiam suas angústias e falavam sobre seus problemas, identificando-se entre si em relação aos sentimentos manifestos. Assim, o grupo foi encerrado e foi realizada a coleta das filmagens de interação pós-intervenção.

$\mathrm{O}$ relato completo dos encontros pode ser observado no Quadro 1.

Quadro 1. Relato dos encontros do grupo

\begin{tabular}{|c|c|c|}
\hline L & Objetivos e estratégias & Percepções e comentários \\
\hline 1 & $\begin{array}{l}\text { Promover entrosamento; elaborar um contrato } \\
\text { definindo as propostas e regras do grupo; discutir } \\
\text { aspectos sobre fala e linguagem. Realizou-se } \\
\text { apresentação do grupo (técnica da placa - cada } \\
\text { mãe deveria se apresentar, enquanto as outras } \\
\text { seguravam placas que deveriam ser levantadas } \\
\text { cada vez que se identificassem com quem estava } \\
\text { falando). }\end{array}$ & $\begin{array}{l}\text { Todas as mães, falaram sobre os filhos, os descrevendo e expondo suas rotinas. Surgi- } \\
\text { ram percepções acerca das relações familiares (processo de infantilização de S1 pela } \\
\text { avó e pelo pai e reduzidas atividades de lazer de M3). No contrato, M1 solicitou que } \\
\text { fossem incluídos itens de discussão como fala e comportamento das crianças. Então, a } \\
\text { fonoaudióloga procurou potencializar a percepção da importância do brincar e diferenciar } \\
\text { fala de linguagem, pois mesmo na ausência de fala tem-se linguagem. M1 mostrou-se } \\
\text { ansiosa, perguntando quando seu filho iria "desenrolar a língua" e começar a falar. M1 } \\
\text { disse que a linguagem é "quando a criança já fala tudo certinho", para M3, a linguagem } \\
\text { "são os primeiros sonzinhos da criança" e a fala "é quando fala tudo certo", M4 não quis } \\
\text { dar uma definição dizendo que estava muito confusa, M1 completou afirmando que } \\
\text { "linguagem é uma forma de comunicação". }\end{array}$ \\
\hline 2 & $\begin{array}{l}\text { Apresentar a psicóloga que auxiliou nos encon- } \\
\text { tros; apresentar M2, que não esteve no grupo } \\
\text { anterior; mostrar às mães estratégias que es- } \\
\text { timulem a linguagem infantil. Utilizou-se material } \\
\text { explicativo sobre estimulação da linguagem, que } \\
\text { foi entregue e comentado pelas participantes. A } \\
\text { psicóloga propôs uma dinâmica que tratava das } \\
\text { dificuldades enfrentadas no dia a dia e o senti- } \\
\text { mento de solidão. Ao som de uma música, cada } \\
\text { uma deveria encher um balão e brincar com ele. } \\
\text { Depois, teriam que trocar de balões, sem deixá- } \\
\text { los cair e, conforme solicitação da psicóloga, } \\
\text { cada uma das mães ia se retirando, sendo que as } \\
\text { outras integrantes teriam que se responsabilizar } \\
\text { pelos balões restantes. }\end{array}$ & $\begin{array}{l}\text { M2 afirmou que vê a brincadeira como o principal meio de alcançar a linguagem, já M1 } \\
\text { afirma que a diretividade é uma forma efetiva de aprendizado. Quando o tópico foi a } \\
\text { infantilização, M1 relatou que sua sogra costuma incentivar que S1 haja desta maneira, } \\
\text { sendo assim, ela proibiu a avó de ficar com a criança até que mude de comportamento; } \\
\text { M2 afirmou que o marido também permite que S2 se comporte desta forma; e M3 relatou } \\
\text { que seu filho (18 anos) costuma tratar S3 como um bebê e a desautoriza algumas vezes. } \\
\text { As mães parecem tentar mudar esta realidade, mas não conseguem e isso as aborrece. } \\
\text { M1 desabafou, dizendo que seu marido "muda de personalidade" e sempre que enfrenta } \\
\text { problemas no trabalho tenta agredir S1. Relatou também, ter tido uma adolescência } \\
\text { difícil (alcoolismo do pai que a agredia). Outra queixa iminente dessa mãe é a falta de } \\
\text { um espaço para discussão. Relacionado à dinâmica dos balões: a psicóloga sugeriu que } \\
\text { as mães imaginassem o balão como sendo as dificuldades e problemas enfrentados. } \\
\text { Assim, quando estavam em grupo, com o auxílio de outras pessoas, ficava mais fácil de } \\
\text { lidar com essas situações (cuidar dos balões) o que se tornava difícil quando estavam } \\
\text { sozinhas. Por isso, a proposta do grupo, contar com uma rede (família) era tão importante. }\end{array}$ \\
\hline
\end{tabular}

(continua...) 
Quadro 1. Relato dos encontros do grupo (continuação)

E

3 Esclarecer às mães questões sobre o desenvolvimento infantil, global e de linguagem, e fazê-las refletir acerca das formas de comunicação e da importância da linguagem. Foi elaborado material sobre o desenvolvimento infantil por faixa etária realização de Técnica não verbal - cada uma deveria sortear uma ficha e através de mímica, indicar o que estava imitando para a colega que teria que interpretá-la.

4 Temática da infantilização; importância do convívio social; audição e seus cuidados.

Novamente, utilizou-se material explicativo, por ser considerado importante pelas mães, que gostavam de levar os folhetos para casa, a fim de mostrar a seus familiares. A partir do material, foi feita discussão dos tópicos.

5 Aproximar mães e filhos melhorando a interação entre eles; incentivar a brincadeira e estimular a criatividade das mães e das crianças.

A estratégia utilizada para atingir os objetivos propostos foi a confecção de brinquedos produzidos com material reciclável. Cada díade mãefilho compunha uma dupla para confeccionar o que quisesse.

6 Propor reflexão acerca dos comportamentos maternos, buscando compreender, interpretar e modificar as atitudes das mães que pudessem estar dificultando o desenvolvimento da linguagem dos filhos. Utilizou-se a visualização das filmagens realizadas no início do processo para discussão em grupo, conforme foi sugerido pelas próprias mães. Foram discutidas as filmagens de M1S1 e M4S4. Buscou-se ilustrar às mães primeiramente os aspectos positivos, para que não se sentissem julgadas ou constrangidas.

7 Teve o mesmo objetivo e as mesmas estratégias do grupo anterior, uma vez que foi a continuação das análises conjuntas das filmagens. A intenção era de avaliarmos as filmagens de M2S2 e M3S3, porém M2 não pôde comparecer devido à problemas de saúde na família.
Percepções e comentários

Estiveram presentes apenas M3 e M4. Durante a leitura, poucos comentários foram feitos por parte das mães. Porém estas se mostraram atenciosas e concordaram com o que foi lido. Posteriormente, a psicóloga propôs uma dinâmica com o intuito de fazer com que as mães vivenciassem a linguagem não verbal e refletissem acerca das diferentes formas de expressão e de como as brincadeiras podem estimular a linguagem. M4 estava mais inibida e teve mais dificuldades durante a dinâmica, no que se refere à imitação, porém, conseguiu interpretar bem o que M3 gestualizava. Observou-se que as mães parecem estar se sentindo mais confiantes quanto ao seu papel e menos apreensivas, em especial, M4 que nesse dia se expressou mais.

Compareceram apenas M1 e M3. Falou-se sobre a proteção excessiva e a importância de dar autonomia e independência às crianças, o que foi comentado por M3, que referiu não ter dado autonomia a seu filho mais velho, o que gerou certa dependência, pois o rapaz sente-se inseguro de realizar suas tarefas sozinho, atitude que ela tenta mudar atualmente na educação de S3. M1 então comentou que sua sogra trata o pai de S1 da mesma maneira: "Quando ele vai na casa dela, ele não levanta pra nada, nem pra botar a comida no prato. Eu perguntei pra ele: Quando tu vai na casa da tua mãe tu vira aleijado?". M4 veio acompanhada do irmão de S4. A primeira a tomar a iniciativa foi M1, que confeccionou uma borboleta. S1 não quis ajudar a mãe na tarefa. M1 referiu então, que S1 prefere brincar sozinho. M4 ficou o tempo todo pensando no que ia fazer, então o irmão de S4 tomou a iniciativa confeccionando um chocalho. M3 passou pelo mesmo que M1, pois S3 não quis ajudá-la, mesmo assim, ela fez alguns desenhos e os colou em uma garrafa, enquanto o filho brincava com S1. Em um dado momento M3 repreendeu o filho, pois ele começou a chutar os objetos. Relacionado a isso, ela referiu que o menino tem "esta mania" porque imita o pai, que tem este hábito. A melhor interação deu-se entre M4 e S4, apesar da falta de iniciativa da mãe, que se mostrou atenciosa aos pedidos do filho e ele, por sua vez, ficava atento e colaborava com as atividades.

M1S1: Mostrou-se a ela, o quanto é positiva a autonomia que ela dá ao filho e os elogios que fez à criança. Percebeu-se que a mãe era bastante pedagógica, nomeando os objetos de forma aleatória, exagerando na articulação e solicitando que ele repetisse ou indagando "o que é isso?". Quando se falou sobre o fato de questionar a criança, M1 afirmou que esta prática é frequente, atribuindo-a a sua ansiedade. Porém, reconheceu que isto é negativo para ambas as partes. As outras mães identificaram-se em relação a este aspecto. M4S4: Esta mãe aproveitou muitas situações em que a iniciativa foi da criança para estimular a linguagem, de maneira espontânea, em contextos bem estruturados, utilizando-se também da especularidade e especularidade diferida. Observou-se que esta mãe soube identificar os pontos que podem ser melhorados na interação. Da mesma forma que M1, M4 algumas vezes questionou à criança "o que é isso?", com relação aos objetos, também atribuindo isto à ansiedade.

M3S3: Já que esta mãe mostrou-se insegura em relação à sua filmagem, a coordenadora buscou enfatizar os aspectos positivos, elogiando a mãe. A fonoaudióloga falou sobre a autonomia que M3 dá ao filho e sobre o fato de aproveitar algumas situações, ampliando os enunciados de S3. Em um segundo momento, a coordenadora alertou M3 acerca dos longos períodos de silêncio da díade, além de algumas cobranças feitas ao menino, como, "o que é isso?" ou "tu não vai falar pra mãe o que é?". M3 mostrou-se contente com os elogios e disse que era difícil criar S3 porque mesmo ela já tendo três filhos adultos, este foi o primeiro que ela cuidou, pois os outros foram criados por babás enquanto ela trabalhava. Já que este encontro foi a última sessão em grupo, a fonoaudióloga questionou às mães como foi a experiência. $M 1$ relatou que mudou em relação a $S 1$, tendo mais paciência e cobrando menos, além de sentir falta nos dias em que não brinca com ele. Ressaltase que foram observadas muitas diferenças no comportamento de ambos no decorrer dos encontros: ele passou a convidá-la espontaneamente a participar das brincadeiras, mostrando-se afetivo e atencioso a ela. M4 emocionou-se ao falar que em sua casa, todos mudaram a conduta. Segundo ela, todos os familiares o infantilizavam, o que foi modificado após as discussões do grupo, que eram comentadas por ela em casa. Além disso, ela referiu que respeita mais as iniciativas de $S 4$ e sabe da importância do brincar. Após a mudança dos familiares, o menino ampliou o vocabulário. M3, afirmou apenas que agora sabe agir melhor em relação ao filho, mas não notou diferenças na criança.

(continua...) 
Quadro 1. Relato dos encontros do grupo (continuação)

\begin{tabular}{|c|c|c|}
\hline$E$ & Objetivos e estratégias & Percepções e comentários \\
\hline 8 & $\begin{array}{l}\text { Objetivou-se analisar a interação de M2S2, da } \\
\text { mesma forma feita anteriormente. Foi marcada } \\
\text { uma sessão individual com M2, a fim de que fosse } \\
\text { discutida a primeira filmagem, já que a mãe havia } \\
\text { faltado no grupo anterior. }\end{array}$ & $\begin{array}{l}\text { Abordou-se a diretividade intrusiva que esta mãe utiliza. M2 foi indagada sobre a razão } \\
\text { que a faz agir assim, então, ela declarou que as pessoas Ihe dizem que S2 não é normal, } \\
\text { pois ainda não fala. Ela afirmou que se sente pressionada por essas pessoas. Sugeriu-se } \\
\text { então, que ela pensasse que relação isto tinha com o comportamento dela em relação ao } \\
\text { filho, e imediatamente ela afirmou que faz com S2 o mesmo que fazem com ela, ou seja, } \\
\text { a deixam ansiosa e fazem com que ela sinta-se pressionada. A partir daí, a fonoaudióloga } \\
\text { tentou tranquilizá-la e buscou valorizar seu papel como mãe. Foi mostrado para M2 a } \\
\text { diferença do comportamento de S2 quando ela age diretivamente e quando ela aceita } \\
\text { suas sugestões de brincadeira e conversa sem fazer indagações desnecessárias. Então, } \\
\text { M2 relatou que é perceptível esta diferença, pois o filho participa ativamente da interação } \\
\text { quando não sofre cobranças. }\end{array}$ \\
\hline
\end{tabular}

Legenda: $\mathrm{E}=$ Encontro

\section{Análise final das interações dialógicas das díades}

\section{Díade 1}

Selecionou-se um segmento que ilustrasse a interação de M1-S1 pós-intervenção em grupo (Sequência 5):

M1: (Coloca uma panela sobre o fogão) Bota uma aguinha ali pra esquentar.

S1: Mamá nenê?

M1: Pra dá mamá pro nenê, mas não tem nem mamadeira aqui.

S1: Hãn?

M1: Não tem mamadeira aqui.

S1: Mamá ó. (Pega peças de um brinquedo de encaixe e finge que é a mamadeira)

M1: Ah! Vamos fazer esse de mamá? A mamadeira é esse?"

S1: $E^{\prime}$

M1: Oba! Então tá! Agora já tem mamadeira.

S1: Hãn?

M1: Agora nós temos uma mamadeira. Tá! E a panela?Tu não tá mexendo? Vai queimar!

S1: Hãn?

M1: Vai queimar a comida.

A linguagem oral começa a emergir neste sujeito, que parece mais engajado em falar. Antes gesticulava mais e, diante da falta de atenção materna ou correção excessiva, desistia. A mãe também apresenta mudança de comportamento e se esforça mais para interagir com o filho, embora com certas dificuldades e ainda com tendência a pedir informações do tipo "o que é isso?", além de algumas atitudes pedagógicas. Agora, um aspecto positivo é o brincar, pois antes a criança convocava a mãe com gestos, palavras e olhar e esta permanecia sentada ou mandava ele não estragar os brinquedos. Antes, o menino simbolizava que um objeto representava algo e a mãe corrigia, já, nesta segunda filmagem, a mãe entrou no faz-de-conta de $\mathrm{S} 1$, fingindo que as peças de encaixe eram uma mamadeira.

Em termos de funcionamento de linguagem percebe-se a presença de um diálogo que ancora a construção gramatical, via processos metafóricos e metonímicos. Esse fato fica claro nos primeiros três enunciados em que S1 enuncia "Mamá nenêe?" e a mãe estende o enunciado para "Pra dá mamá pro nenê", engatilhando a sequência dialogal e favorecendo o retorno de uma fala mais completa gramaticalmente, pelo acréscimo do verbo e preposições. Embora predomine a posição discursiva de pólo do outro no diálogo desta criança com a mãe, já se abrem possibilidades para o surgimento de uma posição na qual o pólo será a língua, pela produção das primeiras frases, o que permitirá a construção do conhecimento gramatical por parte deste sujeito.

\section{Díade 2}

A Sequência 6 demonstra melhor este segundo momento:

S2: Vo lá. (Puxa um jacaré com rodinhas)

M2: Vai aonde? Vai passear?

S2: Não.

M2: Vai?

S2: (Mostra o tênis desatado) Ah não mãe!

M2: (Ata o tênis)

S2: .... и саиô?

M2: Vamos passear de carro?

S2: Não.

M2: Não?

S2: Cauô! (Vai em direção ao carro e no caminho encontra o trem) Teim!

M2: Olha o trem!

S2: Piuí!!!

S2 se esforça para conseguir expressar verbalmente o que deseja (antes falava rápido e utilizava mais gestos para se comunicar), sendo que seu vocabulário está mais amplo. A mãe também parece mais tranquila e consegue compreender melhor a criança. Nos comportamentos maternos houve mudança significativa no brincar entre mãe e filho, pois agora esta participa mais e consegue entrar faz-de-conta com a criança. Esta mudança sugere que o momento de troca e escuta proporcionado pelo grupo pôde abrandar a angústia materna em relação à fala de $\mathrm{S} 2$, ajudando-a a respeitar o tempo da criança, fazendo emergir a linguagem oral.

Este sujeito ainda ocupa uma posição discursiva de pólo do outro, mas já produz enunciados em que comunica autonomamente o que vai fazer como "Vô lá" ou em "Ah não mãe!", o que anuncia o surgimento de uma análise gramatical.

\section{Díade 3}

A Sequência 7 ilustra este momento:

(Brincam com um telefone de brinquedo)

M3: (Coloca o fone no gancho) Ó! Liga pra vovó.

S3: (Fica olhando o brinquedo) 
M3: Tira o fone. Tira o fone. Fala com a vovó. (Coloca o

fone na orelha da criança)

S3: (Pega o fone da mão da mãe)

M3: Fala com a vovó!

S3: (Recoloca o fone no gancho, logo o retira novamente e posiciona para falar) $\hat{O} !$

M3: Alô vovó!

S3: Ô bobó! (Recoloca o fone no gancho)

M3: Dá beijo pra vovó. Beijo pra vovó.

S3: (Posiciona o fone na orelha novamente) $\hat{O} !$

M3: Alô vovó! Diz beijo!

S3: (Estala os lábios mandando beijo e fala algo ininteligível)

Surge o brincar simbólico na interação entre mãe e filho. A mãe demonstra novamente, não se sentir à vontade brincando com o filho, mas busca mais por esse contato. S3 procura brincar mais e se comunica tanto por meio de gestos quanto verbalmente, embora sua fala seja de difícil compreensão. Ao invés de ficar explorando a sala e os objetos ele brinca com esses. O seu olhar se alterna entre o rosto da mãe e os objetos.

A mãe, por sua vez, ancora mais a linguagem do filho, o que se pode notar na sequência do telefonema para a avó que o menino esboça um alô ("Ô") e a mãe o estende ("Alô vovó") e o menino espelha ("Ô bobó"). Embora com muita dependência discursiva (pólo do outro), começa a entrar no funcionamento linguístico.

\section{Díade 4}

Selecionou-se a Sequência 8 para mostrar a evolução de M4-S4:

(Conversavam sobre desenhos animados)

S4: Vê! Pipau Vê Tom. (Faz onomatopéia)

M4: Homem Aranha?

S4: Não! (Repete onomatopéia)

M4: Ah! O Carros?

S4: Aham.

M4: Tu olha o Carros? E o outro? Aquele que tu olha de tardezinha o..

S4: Tom?

M4: Não aquele do... . Como é que éo?"

S4: Hãn?

M4: Como é que é o... Agora não me lembro. Agora não sei.

S4: Alukike!

M4: Hello Kitty?

S4: Aham.

Observa-se alternância de turnos na díade, indicando que a mãe está conseguindo cativar a atenção da criança e ele interessa-se mais em comunicar-se, mostrando significativa melhora na fluência. M4 mostra mais respeito pelo desejo do menino, perguntando do que ele gostaria de brincar, diferentemente da primeira filmagem, em que solicitava que $\mathrm{S} 4$ falasse ou brincasse com o objeto que ela introduziu, mas não era foco de atenção do filho.

Apresentou-se mais disposta a participar do brincar do filho e menos diretiva, embora ainda faça perguntas do tipo "o que é isso?". Interessante observar nos últimos enunciados da sequência que a fala, um tanto ininteligível de $\mathrm{S} 4$, não fica à deriva, sendo interpretada pela mãe, como em "Hello Kitty".
O detalhe importante desta interpretação é que a mãe solicita confirmação do filho, abrindo espaço para o surgimento de uma reflexão futura no menino sobre o quão o outro consegue ou não interpretar o que ele fala. Esse fato o fará ocupar a posição de falante-ouvinte futuramente. Nesse momento ainda ocupa predominante a posição de pólo do outro.

De modo geral, todas as mães ao início apresentavam cobranças às crianças para que falassem e pedidos de informação como "o que?", bem como dificuldades em brincar com os filhos, atendo-se a nomear e mostrar objetos, como se desejassem ensinar as palavras. Ao final da pesquisa, todas mudaram em relação ao seu comportamento com o filho e ao brincar, embora para algumas como M2 e M4 essas modificações foram mais importantes, o que pode repercutir positivamente no desenvolvimento da linguagem oral das crianças.

As mães passaram a valorizar o seu papel como cuidadoras e a importância do brincar para o desenvolvimento infantil, o que se pôde perceber na filmagem que sucedeu aos encontros grupais. A evolução das interações não se deu somente na linguagem oral, mas também no aparecimento de um brincar mais organizado e simbólico.

\section{DISCUSSÃO}

O primeiro procedimento realizado, as entrevistas, permitiu que as mães enunciassem uma queixa, cuja resolução era antes atribuída ao profissional fonoaudiólogo. Juntamente com a queixa, foi trazida também a demanda, por meio do histórico familiar associado a esta queixa, fazendo emergir os sentimentos parentais acerca das circunstâncias apresentadas e demonstrando os desejos das mães em relação ao comportamento dos filhos ${ }^{(2,9)}$.

A ausência de oralidade dos filhos revelou, em todas as mães, sentimentos de ansiedade e desapontamento. Sabe-se da importância do ingresso na linguagem para abrandar a ansiedade materna, uma vez que a fala da criança indica seus sentimentos e suas necessidades, além de contribuir para a interação mãe-criança e para o comportamento exploratório ${ }^{(15)}$.

Por outro lado, as mães podem utilizar o não-falar do filho como uma forma de ligação com ele, uma vez que a ausência de oralidade implica que a criança dependa do que dizem dela (em geral do que a mãe diz), o que foi observado em M3, que apesar de estar distante de $\mathrm{S} 3$, no momento da interação não demonstrava interesse em permitir a sua subjetivação, mesmo "sentindo-se sufocada" por ele em alguns momentos ${ }^{(2,8)}$.

Outra problemática trazida pelas mães foi a dificuldade para estabelecer limites, ora temendo que as crianças tomassem conta da situação, ora temendo estarem sendo demasiadamente rígidas. Especialmente M1, que se sentia mais confusa diante do comportamento de super proteção do pai e da avó de $\mathrm{S}^{(15)}$, reagindo ao comportamento paterno, através de excessiva diretividade, sendo muitas vezes intrusiva, trazendo comandos e reprovações negativas frente às atitudes do filho.

A distância inicial encontrada entre M1 e S1, que parece refletir a difícil relação que esta teve com seus pais, conforme relato feito no grupo: "quando o meu pai bebia e agredia a gente, a mãe nunca ficava do nosso lado, até um dia que eu perguntei pra ela 'tu prefere ele ou as tuas filhas?'”. Havia uma carência de ser acolhida por alguém ("até quando eu 
tava grávida, eu sempre fiz as coisas sozinha, o meu marido sempre ficou na dele"). Tal acolhimento ocorreu no grupo, espaço no qual ela pôde ser ouvida, aproveitando os momentos de discussão para falar sobre seus problemas familiares, para explicitar suas necessidades específicas, que não estavam relacionadas ao propósito principal do grupo ${ }^{(8,13)}$.

Considerando os encontros grupais, já em um primeiro momento foi possível observar a manifestação de sentimentos e exposição dos fantasmas maternos relacionados à fala, iniciando o processo de identidade grupal, tornando o grupo continente das angústias e necessidades de todas as mães ${ }^{(13)}$. Pode-se incluir aqui o conceito de empoderamento, processo que promove o aumento do poder pessoal e coletivo de indivíduos e grupos sociais nas relações interpessoais e institucionais. Este parece ter permitido que as mães entendessem melhor o papel da figura materna no desenvolvimento infantil no confronto das visões no grupo ${ }^{(13,14)}$. As mudanças ocorridas na interação entre mães e filhos, pode ser atribuída ao fato de o trabalho grupal nos contextos comunitários realçar as potencialidades do grupo como um contexto fomentador de transformação e ferramenta de mudança individual ${ }^{(13,14)}$.

Para alguns autores ${ }^{(1,2,12)}$, a falta de atribuição de significados e intenções ao comportamento da criança por parte do adulto parece ser muito danosa à dialogia. Os casos apresentados, neste estudo, confirmam esta hipótese, uma vez que na análise das filmagens foi possível observar (exceto em S3), várias tentativas de interação por parte das crianças, as quais não foram acolhidas pelas mães, que pareciam estar mais preocupadas em ensinar os filhos a falar corretamente, fazendo com que eles se afastassem delas e passassem a brincar sozinhos. Após a intervenção em grupo, esta postura mudou qualitativamente em todas as mães, o que gerou melhoria na interação e maior número de trocas de turnos entre as díades, uma vez que as mães passaram a dar resposta às demandas infantis. A evolução das crianças, demonstrada através das interações, por sua vez, parece ter auxiliado no alívio dos sintomas parentais ${ }^{(2)}$.
A partir dos relatos descritos, fica evidente a importância da interface entre a Fonoaudiologia e a Psicanálise, pois vínculo mãe-filho e desenvolvimento da linguagem são extremamente relacionados. Também o referencial teórico psicanalítico possibilita ao fonoaudiólogo escutar para além daquilo que é dito, assumindo a existência do sentido na alma da palavra ${ }^{(9)}$, percebendo que, em todos os casos, há uma demanda por trás da queixa, que necessita ser interpretada, para que possam ser efetivas as mudanças planejadas pela terapia.

\section{COMENTÁRIOS FINAIS}

Verificou-se com este estudo que a intervenção em grupo com mães de crianças que apresentam alterações de linguagem foi uma estratégia efetiva na melhoria da interação entre as díades relatadas, o que pode ser fator de promoção de melhor desempenho de linguagem das crianças.

No que tange aos comportamentos maternos, esta intervenção mostrou-se comprovadamente eficaz, tanto no sentido de aprimorar a interação das mães com as crianças, mostrando a importância de sua figura no desenvolvimento infantil, quanto no sentido de dar acolhimento às demandas maternas.

Ressalta-se que a intervenção aqui relatada não descarta a necessidade de intervenção terapêutica direta com a criança. No entanto, as mesmas podem ocorrer, após ou em conjunto com a experiência grupal, que pode proporcionar uma mudança no exercício da função materna e, indiretamente, paterna, já que os aspectos trabalhados no grupo podem ter um efeito familiar. As mudanças verificadas na dialogia permitem que a criança vá recebendo, na família, a ancoragem linguística necessária até se iniciar intervenção individual com a mesma e sua família, mas também pode ser muito pertinente durante este processo, já que o trabalho familiar deve ser contínuo.

Destaca-se ainda que os resultados obtidos com este estudo são referentes às quatro díades pesquisadas, não podendo ser generalizada a eficiência deste tipo de intervenção.

\begin{abstract}
The aim of this study was to investigate the efficiency of a group therapy approach with mothers of subjects with language impairment to promote changes in the dialogic interaction of the mother-child dyad. Four mother-child dyads participated in this study. The procedures were an initial interview with the mothers and filming of the dyads engaged in an interaction situation before and after therapeutic intervention, in order to interpret the mother's speech and the dialogic activity, as well as to verify the efficacy of group sessions. Group therapy consisted of eight meetings with the mothers, in which varied issues regarding child development were discussed. The results showed that the intervention improved mother-child interaction. The group therapy approach not only helped mothers in their role, welcoming their demands, but was also an important alternative in clinics of the public health system, since it can reduce the waiting time for Speech-Language Pathology assistance.
\end{abstract}

Keywords: Speech therapy; Child; Mothers; Language disorders; Mother-child relations; Psychotherapy, group

\title{
REFERÊNCIAS
}

1. Mancopes R. Falantes tardios ou atraso de linguagem? Reflexões entre a lingüística e a fonoaudiologia. Desenredo. 2006;2(2):288-306.
2. Vorcaro A. A clínica psicanalítica e fonoaudiológica com crianças que não falam. Distúrb Comun. 2003;15(2):265-87. 
3. Terçariol D. A clínica fonoaudiológica: da prática à construção de fundamentos teórico-metodológicos. In: Graña CG. Quando a fala falta: fonoaudiologia, linguística e psicanálise. São Paulo: Casa do Psicólogo; 2008. p. 79-94.

4. Broomfield J, Dodd B. Children with speech and language disability: caseload characteristics. Int J Lang Commun Disord. 2004;39(3):30324

5. van Daal J, Verhoeven L, van Balkom H. Subtypes of severe speech and language impairments: psychometric evidence from 4-year-old children in The Netherlands. J Speech Lang Hear Res. 2004;47(6):1411-23.

6. Keilmann A, Braun L, Schöler H. [Diagnosis and differentiation of children with language development disorders. What role can be attributed to intelligence?] HNO. 2005;53(3):268-84. German.

7. Markiewicz K, Pachalska M. Diagnosis of severe developmental disorders in children under three years of age. Med Sci Monit. 2007;13(2):CR89-99.

8. Winnicott DW. Da pediatria à psicanálise: obras escolhidas. Rio de Janeiro: Imago; 2000.

9. Ieto V, Cunha MC. Queixa, demanda e desejo na clínica fonoaudiológica: um estudo de caso clínico. Rev Soc Bras Fonoaudiol. 2007;12(4):329-34.
10. Rannard A, Lyons C, Glenn S. Parent concerns and professional responses: the case of specific language impairment. Br J Gen Pract. 2005;55(518):710-4.

11. Rannard A, Lyons C, Glenn S. Children with specific language impairment: parental accounts of the early years. J Child Health Care. 2004;8(2):165-76

12. Lemos CTG. Os processos metafóricos e metonímicos como mecanismos de mudança. Substratum. 1992;1(3):151-72.

13. Zimerman D. A importância dos grupos na saúde, cultura e diversidade. Vínculo. 2007;4(4):1-16.

14. Moreira MD. A orientação fonoaudiológica a pais e a capacitação da linguagem de seus filhos [dissertação]. Santa Maria: Universidade Federal de Santa Maria. Programa de Pós-graduação em Distúrbios da Comunicação Humana; 2007.

15. Lopes RCS, Oliveira DS, Vivian AG, Bohmgahren LMC, Piccinini CA, Tudge J. Sentimentos maternos frente ao desenvolvimento da criança aos 12 meses: convivendo com as novas aquisições infantis. Psicol Teor Pesqui. 2007;23(1):5-15. 